\title{
Validating the Addiction Severity Index (ASI-6) on Offender Re-Arrest
}

\author{
Michael Seredycz* \\ Department of Sociology, MacEwan University, Canada
}

Submission: February 12, 2020; Published: March 04, 2020

"Corresponding author: Michael Seredycz, Assistant Professor, Department of Sociology, MacEwan University, 10700 104th Avenue Edmonton, Alberta, Canada

\section{Abstract}

This study validates the use of the ASI-6 (Addiction Severity Index, version 6) as a practical risk assessment tool to predict short and long term offender re-arrest. The ASI- 6 conservatively predicted between $43 \%$ and $58 \%$ of offender re-arrest within one, three- and five-year intervals (not taking into account demographic variables). This study utilizes offender intake data from 434 offenders within an Access to Recovery (ATR) substance abuse program with municipal, county and state correctional data on re-arrest. Offenders who scored highly within each of the seven domains of the ASI-6 metrics were also found to be more likely to be re-arrested over one, three and/or five years post release from custody.

Keywords: Addiction severity index ASI-6; Access to recovery ATR; Substance use; Recidivism; Re-arrest; Probation; Parole

\section{Introduction}

The ability of any offender to self-correct and/or rehabilitate oneself with the stigma of an arrest, conviction and/or incarceration is difficult. Most offenders will cycle through the system like an assembly line (Packer, 1968) with barriers for reintegration either improperly prioritized or left untreated [1]. Each States' correctional system operate differently and as such the processes and outcomes of intake personnel as well as probation and parole officers (and their caseloads) vary widely. Offenders will often have so many barriers to reintegration that they may not self-report and/or probation/ parole or case managers may be unable to determine the best course/ pathway to reduce future offending. This study sheds more light on the intake process and the Addiction Severity Index, version 6 ASI-6). The ASI-6 should be considered a risk assessment tool which can identify and prioritize offender risks and needs assisting practitioners on how to profile or classify offenders at the highest risk of reoffending. As probation/ parole officers face escalating caseloads, the ASI6 could assist in determining how to prioritize/ classify those at higher risk, what interventions are the most important, while also ascertaining appropriate time, supervision and resource allocation. Many practitioners that work with offenders often see more failure than success and could easily buy in to Robert Martinson's "nothing works" (1974). However, it should be noted that we do know what works, what does not and what is promising
[1]. Utilizing data, statistics and analytics is not a new idea in assisting those within the criminal justice system. Comparing success and failure might be easier if we consider using American's favorite pastime, baseball as an analogy. The movie Moneyball [2] was inspired by a book written by Michael Lewis in [3] that articulates the need and use for analytics in baseball. Moneyball [2] credited Bill James as a pioneer for baseball analytics, which James coined as Sabermetrics; Society for American Baseball Research [4]. Sabermetrics was designed to develop quantitative measurement to baseball games and players to determine how to use resources appropriately to generate wins [4].

The use of analytics and resource allocation was slow to be implemented within baseball as the 2012 movie Moneyball reflected. However, today, every Major League Baseball (MLB) team utilizes analytics for a variety of ways to determine matchups and scenarios based on odds [4]. Multivariate analysis operates in the same fashion using odds and prediction. Perhaps in the not so distant future, correctional data analytics will predict the best scenario fits for practitioners and the typology of offenders to ensure success over failure. Moneyball explains resource allocation [3]. Success for any baseball player at the homefield plate is a base hit, when compiled is a batting average. Consider that there is no player in MLB history with over 100 at bats any given year has ever hit 500 batting average. Excellent players who 
hit a 300-batting average over a lifetime fail seven times out of ten to get a base hit. Failure is more a part of the game of baseball than success. Major league hitters would not likely subscribe to nothing works. Why should probation/ parole officers or other criminal justice practitioners be any different than baseball players? Accepting failure should not be an option. Addiction Severity Index (ASI-6) The Addiction Severity Index (ASI) was first introduced in the United States as a clinical tool to assess the incidence and prevalence of substance use and co-occurring impairments (McLellan et al, 1980). The validity, reliability and consistency of the ASI have been reported in hundreds of studies [5] and the ASI's celebrity status led to it being translated into different languages and adopted by other European countries [6].

The European Union's cost A-6 program revised the ASI by modifying composite scoring to develop a more specific European version [7,8]. McLellan et al. (2002:211) suggest that "the ASI has been shown to be reliable and valid among substance abusers applying for treatment". Cacciola et al. $[9,10]$ also report that the ASI has been shown to be a reliable and valid clinical instrument while also being utilized in a wide variety of clinical populations and treatment settings. Other scholarly research argues that the ASI has also been a reliable predictor in assisting different demographics of peoples [8]. This tool has been generally utilized to target different inpatient, outpatient and residential settings (Makela, 2004) and thus required a sixth edition for modification of language and query based items inquiring more about a participant's cognitive processing Cacciola et al. $[9,10]$ found that the ASI was also a good predictor of antisocial behavior. Another study by Cacciola and his colleagues found that the ASI was a good predictor for clients with co-occurring psychopathology (2001), widening the scale of its usage. Lesieur \& Blume [11] found the ASI could assist in the prediction of pathological compulsive gambling patterns. While this study used a modified ASI, the participants were found to have reduced their intake of alcohol and other drug use in addition to gambling. Participants were also found to have improved legal, family/social, and psychological functioning Lesieur \& Blume [11]. These versions of the ASI were initially designed to identify risk levels of alcohol and other drug abuse and subsequent domains associated with substance use [12] however, there are few, if any, studies that utilize this tool to predict future criminality. The primary purpose of the ASI was to determine a participant's level of risk and/or needs to best prioritize process and/or outcomes-based treatment. This is consistent with the works of Andrews et al. $[13,14]$ as they assert that identifying risk, determining needs and appropriate responses (based on evidence-based research) is fundamental in assisting offenders reintegrate back into their communities. Andrews et al. [13,14] are similar to other researchers in the field promoting the use of statistics and analytics in determine success versus failure for offender criminal desistence. Andrews et al. $[13,14]$ also recognize the discretion of practitioners in the field (override) to determine what may work best with any given person taking into account the situations and context that may exist in their rehabilitation
[15]. Therefore, it could be argued that the ASI has been utilized to ascertain participant clinical options, similar to Andrews et al. RNR model [15]. The ASI could operate to assist probation/ parole/ case managers in resource allocation in the same way it has been utilized as an administrative tool in determining resource allocation for therapy $[12,16,17]$.

\section{offender desistence from crime}

Why do offenders fail at desistence from crime? Perhaps one significant reason is that probation and parole officers have historically been over-burdened with larger caseloads due to an influx of offenders cycling and reintegrating to their communities' post - incarceration [18]. Effective classification has been shown to reduce reoffending by as much as $30 \%[13,14]$. Caseloads once thought to be maxed out at 80 per probation/ parole officer are becoming less manageable with agents expected to do more intensive supervision [19]. The incarceration of approximately 2.3 million people in jails and prisons across the United States [20] has only added more stress on the community based correctional system. Almost everyone, approximately $98 \%$ of people, admitted to correctional facilities will return to their communities at some point $[18,21]$. About seven million offenders were under some form of adult correctional system supervision equating to one in every thirty-five adults in the United States [22]. Nearly 3\% of all adult residents in America were on probation or parole and/ or incarcerated in jail or prison [22]. Beck (2006) suggests that nearly nine million people will be released any given year from jails across the United States. The simple solution is obviously to have a less punitive criminal justice system however this solution is likely generations away from fruition. Therefore, immediate solutions need to be implemented to simply sustain the institutional and community based system's operation at a local level to assist probation/ parole agents to best profile the offenders in their care while allocating resources with lesser waste to the system and potentially to each offender. The use of the Addiction Severity Index, version 6 (ASI-6) should assist intake facilitators and probation/parole officers in better determining the risk needs and assessment of offenders to better ascertain levels of direct and indirect supervision, outcomes and resource allocation. As explained previously, developing typologies and profiling of offenders can determine future success and/or failure (Ericson, 2007) [23,24].

Utilizing statistics and analytics to develop typologies or profiles of offenders is the next step in assisting offenders while also increasing success. However, as in the MLB baseball analogy explained previously, institutional change requires buy in. Rothstein et al. [25] reported that probation and/or parole officer's discretion have become such institutional practice that they are synonymous with the generation of success and failure outcomes. These institutional measurements could more likely that not be attributed to the decision making of the officer and not the empirical or observable measurement of the offender $[23,26]$. Hannah-Moffit et al. [24] suggests that the use of discretion can 
even further insulate probation and parole officers from utilizing more empirical instruments as an institutional practice.

\section{Profiling offenders using the ASI-6}

The Addiction Severity Index was designed to assess seven problem areas typically found among those people who are using or abusing alcohol and other drug abuse [12]. Utilizing 118 indepth questions, intake screeners would be expected to assess intake participants in seven core areas: one's

(i) Medical condition;

(ii) Employment and support;

(iii) Incidences and prevalence of alcohol use and

(iv) Drug use;

(v) Legal status;

(vi) Family relations;

(vii) Psychological/psychiatric status.

It should be noted that all of the seven core areas have been indirectly or directly related to criminal reoffending $[1,21]$. Questions utilize different intervals to determine the frequency and duration of the topical areas which include last occurrence, monthly, over six months and lifetime prevalence. Domain questions document a measurable and calculated type, duration, and frequency of problems. This is followed by Likert based questions to determine how these issues impact the respondent. The ASI was designed to take approximately 45 to 60 minutes in a semi-structured interview administered by a trained intake clinician, who is expected to spend another 10 to 20 minutes scoring each participant's responses [12]. Within each domain area, a composite score is derived from several of the questions that were asked by the interviewer. The composite scores are considered measures of problem severity, with higher scores indicating greater problem severity. The clinical aim of the ASI is to identify treatment needs within each domain $[27,28]$. Obviously, the higher the risk and need of any of the offender's seven domains the higher the anticipated likelihood of future re-arrest.

Re-arrest was utilized as the recidivism variable because it is the most commonly and effectively used measurement [29-31]. Re-arrest, for the purpose of this study, refers to any arrest for a misdemeanor or felony charge. The most recent national study on reoffending is a sample population of approximately 404,000 offenders released in 23 States in 2005. DuRose et al. [29] found that four of ten offenders (43.4\%) would be re-arrested within their first year of release. This number of offenders re-arrested continues to escalate to $67.8 \%$ after a three-year follow-up and furthermore to $76.6 \%$ of offenders re-arrested after five years. While the re-arrest rates varied by the type of offender, the glaring issue is that nearly three quarters of those on probation or parole will be re-arrested in five years (2014:2). As stated above, this could be viewed as a significant failure of the system but if it was baseball, we may want to reverse how we approach rehabilitation and reintegration. Over half $(56.5 \%)$ of offenders were successful in not being re-arrested of a new crime in the first year after release from custody. However, these numbers begin to drop over a three and five year interval suggesting that more resources are necessary either in the first year of working with probation/ parole agents and/or a continuum of care of services and resources to sustain their success from desisting from crime. Therefore, success is possible, we simply need to learn more about the barriers that offenders face, rather than simply the recidivism outcomes [32].

\section{Methodology of the Current Study}

This study utilizes data collected from a federally funded Access to Recovery site within the Midwest United States. Access to Recovery (ATR) was a grantee voucher program for substance abuse clinical treatment and recovery support services [33]. Probation and parole officers would recommend offenders for this program due almost entirely of an influx of services available. While the criteria for the program was to reduce alcohol and other drug abuse which should reduce criminal activity [34], not every offender had a significant substance abuse issue. Inclusion criteria for offender participation in this Access to Recovery site study were:

a) adults aged 18 or older;

b) residents of the ATR site city,

c) a need for alcohol and/or drug treatment; and

d) agreement to sign informed consent.

Die to the pronounced amount of resources offered in the ATR program, there was heavy demand for any and all services the ATR program provided. However, due to a lack of ATR funding and resources, not every offender was offered this opportunity and as many as eight hundred offenders were wait listed for the program at any given time. Upon acceptance into the program (prior to their release from jail or prison), offenders would receive a referral to a clinic with an intake specialist within a 24-48 hour period. Probationers and parolees would further be assessed and screened at an intake clinic using the Addiction Severity Index, version 6 (ASI-6) prior to being provided a list of recommended alcohol and drug abuse treatment providers that offenders could select from. The ASI-6 and its seven composite scores were provided to social service case managers, treatment clinicians and probation and parole officers [33]. Overall, 434 offenders met the criteria over the first year of the site's operation and were used for this analysis. The total number of possible jail and prison released offenders who tried to access the program was 456 that year however, records and documentation of 22 offenders who participated in the program were illegible and removed from the analysis. This study utilized a one group one shot treatment design. This design involved the exposure of a group of offenders 
to a wide variety of treatment and rehabilitative programs which was further followed by a measurement of criminal desistence. This varies significantly from a true experimental design in that there was no control group in which to make comparisons. Additionally, there was no random selection of offenders as every offender who wished to participate in the program was included in the analysis. As such, these limitations should be taken into account when considering the findings $[1,35]$.

To assess reoffending, a conceptualized version of re-arrest was utilized at various one, three- and five-year intervals. As explained previously, of all recidivism variables collected by the Bureau of Justice Statistics (2014), re-arrest is considered the most widely accepted measurement. Re-arrest refers to any arrest for a misdemeanor or felony charge. A triangulation of sources was necessary to ensure the validity and reliability of re-arrest. The first and least reliable data source was the selfreported behavior of probationers and parolees. This was either validated or often invalidated through three additional layers of data points. The first and second validation measures were from access to police records from the City Law Enforcement agency and the local County Sheriff's Office where the offender was to reside. Names, aliases, dates of birth and addresses were used as identifiers. The third validation measure was the State's probation/ parole database system which included case notes and contact information for offenders under community supervision. This re-arrest data was merged with ASI- 6 data points to complete more sophisticated analysis. The following section shares the risks and needs associated with the seven ASI-6 domains, the classification of offenders based on risk and furthermore why the ASI-6 is a reliable and valid clinical tool to predict interval levels of offender re-arrest.

\section{Study Findings}

The first section of the study findings provides a glimpse into the sample population's risks and needs initially reported by offenders within an intake session. The ASI- 6 was used to assess offender's histories, frequencies, and consequences based on seven core domains: (i) drug and (ii) alcohol use:, (iii) medical, (iv) employment, (v) legal, (vi) social and family and (vii) psychological functioning. Furthermore, offenders were classified into levels of severity to determine risk levels (that practitioners could use as cut off points). This section will then examine reoffending, reoffending patterns and why the ASI is a good predictor of short-term intervals of re-arrest over one, three- and five-year periods (similar to the Bureau of Justice Statistics as compiled by [29]. Table 1 accentuates the risks and needs that offenders reported thought the Addiction Severity Index, version 6 ASI-6). This table offers a glimpse into the profile of the sample (without including the demographics). Demographic data for the study was excluded so that it does not jeopardize the statistical significance of the validation of the ASI- 6 while also providing a baseline conservative measure for its predictability. If demographic variables were included, we know that there is a statistically significant relationship criminal offending has with sex, age, race and ethnicity [21]. Eight in ten offenders (82\%) reported the drug use domain was an area of need, while $18 \%$ reported no existing problems. However, 74\% of offenders identified alcohol as an area of need. Therefore, this profile of the sample would suggest there are many offenders with co-occurring substance use (either currently or historically). The most prevalent of each of the seven ASI- 6 domains was employment or the lack of it. Nearly every offender, $98 \%$ reported this as an area of need. As such, this domain seemed to be a well expressed and significant barrier to reintegration. Surprisingly, only $77 \%$ of offenders reported the legal domain as an area of concern. To reiterate, this domain was captured through intake interviews and there was the possibility for offenders to be less truthful about their criminal history. Nearly two in ten offenders were not as honest within the ASI-6 which does indicate the ASI- 6 obvious limitation: self-reporting. This is also why generating rapport between intake assessors and offenders are vital for determining risk [24]. A majority of offenders also reported the need for social and/or family support assistance (69\%), psychological or mental health assistance (60\%) and/or a reported medical need (45\%). The ASI-6 risk/ needs assessment should provide case managers, clinicians and probation/parole officers an opportunity to profile an offender to determine priority, supervision and resource allocation. However, this was at the discretion of each case manager, treatment clinician and/or probation/parole officer so it is difficult to ascertain if these needs were met.

Table 1: Offender Reported ASI-6 Areas of Need.

\begin{tabular}{|c|c|c|}
\hline 7 ASI Domains & \% & n \\
\hline Employment & $97.90 \%$ & 425 \\
\hline Drug & $81.60 \%$ & 354 \\
\hline Legal & $77.20 \%$ & 335 \\
\hline Alcohol & $74.20 \%$ & 322 \\
\hline Social/ Family & $69.10 \%$ & 300 \\
\hline Psychological & $59.20 \%$ & 257 \\
\hline Medical & $44.70 \%$ & 194 \\
\hline
\end{tabular}

It needs to be noted that there is significant co-occurring risks and needs associated with the offenders represented in the sample. To no probation or parole officer's surprise, offenders will often have many risks and needs that need to be met [24]. Therefore, a follow-up to examining prevalence is to ascertain which of the seven domains are the most severe to appropriately determine a course of action. The literature often focuses on taking a holistic approach to rehabilitation which only reinforces the findings of these study participants. However, where does a probation/ parole officer, case manager or clinician begin? What is the level of resource allocation that each offender needs and what risks are so severe they require immediate intervention versus needs which can wait. This is often the dilemma faced by practitioners assisting 
offenders in determining the appropriate levels of action. A higher composite ASI-6 score within each domain would indicate a greater risk and/or need for treatment or intervention. The scores in Table 2 below were generated to attain a better profile of the sample for probation/parole officers to determine and/or classify offenders based on risk. To better understand the level of severity offenders may face, Table 2 outlines how problematic each of the domains were ranging from an aggregate score from not at all a problem (zero) to an immediate threat to one's safety (one). Each domain has its own aggregate score based on scaled variables of interest (as mentioned previously were high in face validity and reliability).Attaining a score of .01 to .24 would reflect a low area of need and .25 to .49 would indicate a moderate concern, Those offenders scoring between .50 to .74 could be categorized as an escalated or high level of need. Those offenders scoring .75 and above would be categorized as requiring an immediate assistance due to its severity. As Table 2 indicates, there was a relatively good variation within each of domains as to make certain inferences about the sample. However, what becomes more obvious is the association. between prevalence of risk as reported by offenders
(Table 1) and the severity of the risk, which is analyzed through the use of the ASi-6 metrics. Employment is one of the most significant contributors to reoffending (citation). It is obvious that employment is the most significant barrier facing offenders. In terms of prevalence of the problem (98\% reported in Table 1 ) as well as those scoring high (10\%) and severe (84\%) risk on the ASI-6 metrics. Probation/parole agents, case managers and clinicians should all be identifying this risk/need as the number one priority for this sample, above all other factors/ domains. Interestingly enough, medical risk and needs were found to be one of the least likely needs in terms of prevalence (Table $145 \%$ reported) but of those $45 \%$ who reported medical issues, there was significant variation in the risks associated with medical treatment. As such, practitioners may want to consider more indepth referrals to determine what every individual may be facing. The problem may be that due to a lack of universal health care, this will be difficult to attain. One in ten offenders reported an immediate medical need 24-48 hours having been released from custody. This is problematic considering that inmates often attain health care within their facilities.

Table 2: Offender Reported ASI-6 Levels of Severity.

\begin{tabular}{|c|c|c|c|c|c|}
\hline \multirow{2}{*}{ 7 ASI Domains } & \multicolumn{5}{|c|}{ Levels of Severity } \\
\cline { 2 - 6 } & None & Low & Moderate & High & $.50-.74$ \\
\hline & 0 & $.01-.24$ & $.25-.49$ & $9.70 \%$ & $83-1.0$ \\
\hline Employment & $2.10 \%$ & $1.40 \%$ & $3.20 \%$ & $7.80 \%$ & $14.10 \%$ \\
\hline Medical & $55.30 \%$ & $12.40 \%$ & $10.60 \%$ & $15.90 \%$ & $1.60 \%$ \\
\hline Psychological & $40.80 \%$ & $22.10 \%$ & $19.80 \%$ & $15.40 \%$ & $0.70 \%$ \\
\hline Legal & $22.80 \%$ & $30.40 \%$ & $30.60 \%$ & $9.40 \%$ & $2.10 \%$ \\
\hline Alcohol & $25.80 \%$ & $45.60 \%$ & $17.10 \%$ & $5.80 \%$ & $0.90 \%$ \\
\hline Social/ Family & $30.90 \%$ & $41.50 \%$ & $21.00 \%$ & $3.00 \%$ & $1.20 \%$ \\
\hline Drug & $18.40 \%$ & $61.30 \%$ & $16.10 \%$ & & \\
\hline
\end{tabular}

While $60 \%$ of offenders reported a psychological risk/need, nearly one -third $(17.5 \%)$ reported a high or severe need. This might be correlating with research that indicates that mental health, and/or the diagnosis of mental health is on the rise and offenders are not immune. There is also a connection of mental illness with medical care, alcohol and drug abuse and unemployment [21]. Gainful employment could offer benefits that pay for medicalization and/or mental health medications whereas, if one does not have gainful employment, research indicates that people will self-medicate with alcohol or illicit drugs because they may not be able to afford medication [22]. The legal domain, already considered problematic in terms of self-reporting (Table 1) identified a wide variation of legal issues either historically or outstanding. It should be noted that no offenders participating in the program had pending charges upon immediate release from custody and entrance into the Access to Recovery (ATR) program. Therefore, offenders still feel that the terms and conditions of probation/ parole placed on them are problematic and require more assistance. Therefore, practitioners may want to reassure offenders the expectations of probation/ parole and/or their treatment goals. This domain very likely highlights the difference between those offenders who were on probation $(21 \%)$ and those on parole (79\%). Although the Access To Recovery (ATR) program was meant to serve those with alcohol and drug abuse issues which most offenders did say were prevalent, offenders reported lower and more moderate metrics of drug abuse risk, Based on the ASI- 6 metrics, it could be recommended that drug treatment, while potentially effective should be considered a secondary need for the sample population. However, this may contradict various practitioners who believe they may recognize one need over which creates a divide in the best course of action to assist the offender. One practitioner may recommend more intensive treatment which requires 4 hours each day while another practitioner may be recommending an alternative course of action for those 4 hours each day (i.e., employment or vocational training). For this reason, it is important to ensure that risks/needs are prioritized so offenders can be classified and assisted with their own potential needs. 
Of those reporting a social or family need (69\%), a very high percentage felt this was a low or moderate issue that may require assistance or resources. This could be due to lengthier stays of incarceration which has led to a breakdown of the family unit and/or a lessening of trust. These are all issues that may be prevalent in other domains as well. Subsequently, it is still integral to utilize a holistic approach [36]. As explained previously, data markers were triangulated and validated from official police, court and correctional sources in addition to the self-reporting of offenders to measure re-arrest. The triangulation of four data sources determined that 29.5\% (128) of offenders in the Access To Recovery program were re-arrested while completing their rehabilitation/ treatment within their first year of release. This percentage mirrors the national American averages which suggest that within the first six months of the 1994 national recidivism study that $30 \%$ of offenders were re-arrested for a misdemeanor or felony [30]. This is a slightly lower number than the findings by DuRose et al. [29] of $43.4 \%$ of offenders were re-arrested in 23 States.

As seen in Table 3, within a three year follow up period, $52 \%$ (or 228) ATR offenders were re-arrested. This prevalence is substantially lower than the Bureau of Justice Statistics averages of $67.5 \%$ over the national studies done in 1983 and 1994 [20]. This percentage is also dramatically lower than 2005 recent estimates of $67.8 \%$ [29], This might suggest that the sample is irregular or perhaps that offenders who participated in this program simply had lower rates of re-arrest due to factors that are unable to be substantiated as a result of a lack of a comparison group or experimental design). Within the fifth year of follow-up, $59 \%$ (256) of offenders were re-arrested for a misdemeanor or felony. For the purpose of internal validity, it should be noted that no offenders or cases were removed for experimental mortality. In year five, ATR offenders were far less likely to be re-arrested than the reported $76.6 \%$ of State offenders released in 2005 [29]. While Access to Recovery offenders deviated from the national statistics at the third and fifth interval of follow-up, it is difficult to attribute this solely to the program (as there was no local or regional comparison group). Three logistic regression analyses were used to determine the predictability of the ASI- 6 when predicting rearrest over one, three- and five-year follow-up time periods upon completion of the Access to Recovery (ATR) program. To reduce the likelihood of multi-collinearity for each of the regression models, this study ensured the removal of any case outliers with over a 2.0 residual tolerance and Variance Inflation Factor (VIF) over 4 . As such, 11, 12 and 8 cases were removed from each of the three logistic multivariate models.

Table 3: Access to Recovery Offender Re-Arrest.

\begin{tabular}{|c|c|c|c|c|c|c|}
\hline Arrest & \multicolumn{2}{|c|}{ Year 1 } & \multicolumn{2}{c|}{ Year 3 } & \multicolumn{2}{c|}{ Year 5 } \\
\hline & $\%$ & $\mathrm{n}$ & $\%$ & $\mathrm{n}$ & $\%$ & $\mathrm{n}$ \\
\hline Yes & $29.50 \%$ & 128 & $52.50 \%$ & 228 & $59.00 \%$ & 256 \\
\hline No & $70.50 \%$ & 306 & $47.50 \%$ & 206 & $41.00 \%$ & 178 \\
\hline
\end{tabular}

Table 4 illustrates the predictive power of the seven ASI-6 domains on offender re-arrest after one year of release. This model was found to be statistically significant (.001 with a confidence level of $95 \%$ with the $\mathrm{p}<.05$ being significantly different than zero). The domains within the model explain $43 \%$ of re-arrest after one year. This number is based on the average of two variances utilized for the analysis. The well-respected Nagelkerke R Square was reported at .500 and the Cox and Snell R Square was .351. The average between the two, to remain conservative was $43 \%$. The regression reported a Chi-square of 187.92 and a model -2 Log likelihood of 338.53. In addition to the model being significant, each of the domains were also found to be significant using a $95 \%$ confidence interval. Validating the Addiction Severity Index (ASI6) on Offender Re-Arrest The findings of the regression analysis suggest that the metrics associated with those at higher risk within the ASI corresponded to higher Beta values in predicting re-arrest one-year post-release from incarceration. The legal domain had the most impact of each of the seven dimensions of the ASI-6. This was somewhat predictable if we consider that the twenty seven questions pertinent to one's legal status consist of: criminal justice system admission referral, probation/ parole status, previous criminal records (including arrest, conviction and incarceration), as well as cognitive coping of these issues to determine coping mechanisms and/or assistance that needs to be provided. Therefore, practitioners could offer more direction and guidance to offenders to potentially better equip newly released offenders of the expectations of the various persons they will work with, so they do not violate the terms and conditions of their probation/ parole. Again, this domain simply highlights the difference between those offenders who were on probation $(21 \%)$ and those on parole (79\%).

Table 4: Domains Associated with Re-Arrest within the Last Year.

\begin{tabular}{|c|c|c|c|}
\hline 7 ASI Domains & Beta & SE & Sig * \\
\hline Legal & 3.45 & .72 & $.000^{*}$ \\
\hline Employment & 3.09 & .59 & $.000^{*}$ \\
\hline Psychological & 3.07 & .41 & $.00 *^{*}$ \\
\hline Drug & 2.83 & .61 & $.011^{*}$ \\
\hline Alcohol & 2.82 & .70 & $.034^{*}$ \\
\hline Social/ Family & 2.57 & .53 & $.022^{*}$ \\
\hline Medical & 2.32 & .39 & $.010^{*}$ \\
\hline Constant & -1.38 & .83 & $.000^{*}$ \\
\hline
\end{tabular}

Employment, or the lack of employment opportunities remains a significant barrier for offenders. Those reporting higher levels of risk were also more likely to be re-arrested within the first year of their release from custody. We recognize that employment is one of the best predictors of recidivism and it appears that offenders recognized this as well as they self-reported significant levels of need and risk. Those offenders who were identified at high risk using the ASI-6 were more likely to be re-arrested within the last one year upon release. Despite the low percentages of those 
Annals of Social Sciences \& Management studies

offenders reporting mental health or psychological issues present, those who scored within the high and severe classifications of the domain were found more likely to be arrested. Therefore, it may be appropriate to assist offenders in identifying the appropriate levels of resources to assist them in identifying the appropriate level of diagnosis, treatment and medication supply. Something unusual is occurring within the ASI metrics of the alcohol and drug use variables and re-arrest. While offenders identified both to be areas of concern within the ASI- 6 domain, a large percentage of the sample did not appear to be at a higher or severe risk for alcohol or drug use (based on their composite scoring). That said, it still appears, based on the data, that those who scored with a higher and severe risk of alcohol or drugs were more likely to be re-arrested. However, for this particular variable, it might be recommended to examine how they may have scored on particular elements of both alcohol and drug use. The drug-crime nexus (Tonry, 1987) is obviously prevalent and statistically significant in this model but far more complex. Despite being enrolled in an ATR substance abuse desistence program, alcohol and drug use remains a prevalent risk factor.

This regression analysis not only indicates that many of the risks/ need's offenders identified are warranted, but it also validates the use of the ASI- 6 as a good predictor of re-arrest one year after an offender leaves custody. All domains appear to be significant and as such if used appropriately, those scoring at high or severe risk of the ASI-6 will be more likely to be rearrested, with the exception of alcohol and drug use (which appears to be a strong determinant based on significant bodies of research). The second model in (Table 5) suggests that the ASI6 was a much better predictor of re-arrest within a three-year follow-up. This model, like the last was found to be statistically significant (.001 with a confidence level of $95 \%$ with the $\mathrm{p}<.05$ being significantly different than zero). The variance explained within this model increased from the previous one-year followup. The first model predicted $43 \%$ of future offender re-arrest. This model predicts approximately $58 \%$ of re-arrest, a significant increase. This number is based on the average of two variances utilized for the analysis. The Nagelkerke R Square was reported at .662 and the Cox and Snell R Square was .496. The regression reported a Chi-square of 297.16 and a model -2 Log likelihood of 303.410. Eerily similar to the first logistic regression all domains of the ASI-6 remained statistically significant in predicting rearrest over a three-year follow-up upon release. Employment remains a strong determinant of re-arrest but it becomes the most significant predictor over a three year period. Therefore, it should be argued, that based on the sample and the level of risk associated with offender self-reporting, employment should be a crucial barrier that these offenders should have attained assistance for, In addition to employment, mental health and an offender's legal domain remained significant predictors of rearrest (Table 6). Alcohol and drug use domains also remained statistically significant but again, similar to the first model, were less of a predictor than other factors.
Table 5: Domains Associated with Re-Arrest within the Last Three Years.

\begin{tabular}{|c|c|c|c|}
\hline 7 ASI Domains & Beta & SE & Sig * \\
\hline Employment & 3.98 & 0.87 & $.000^{*}$ \\
\hline Psychological & 3.01 & 0.73 & $.000^{*}$ \\
\hline Legal & 2.79 & 0.81 & $.02 *^{*}$ \\
\hline Drug & 2.28 & 0.22 & $.000^{*}$ \\
\hline Alcohol & 2.16 & 0.82 & $.011^{*}$ \\
\hline Social/ Family & 1.99 & 0.91 & $.005^{*}$ \\
\hline Medical & 1.54 & 0.65 & $.010^{*}$ \\
\hline Constant & -3.23 & 1.09 & 0.064 \\
\hline
\end{tabular}

Table 6: Domains Associated with Re-Arrest within the Last Five Years.

\begin{tabular}{|c|c|c|c|}
\hline 7 ASI Domains & Beta & SE & Sig * \\
\hline Employment & 3.88 & 0.73 & $.002^{*}$ \\
\hline Drug & 2.34 & 1.31 & $.017^{*}$ \\
\hline Legal & 2.11 & 0.82 & $.000^{*}$ \\
\hline Alcohol & 2.02 & 0.75 & $.00 *^{*}$ \\
\hline Psychological & 1.62 & 0.14 & $.041^{*}$ \\
\hline Social/ Family & 1.44 & 0.38 & $.013^{*}$ \\
\hline Medical & 0.88 & 0.52 & $.046^{*}$ \\
\hline Constant & -2.57 & 0.62 & 0 \\
\hline
\end{tabular}

Those offenders scoring high on the ASI-6 for medical assistance and need were also found to be more likely to be rearrested at either the one and/or three-year intervals. That said, there may be a connection between long standing chronic issues of alcohol/ drug use and its physiological consequences [37]. Social and informal family supports remained a statistically significant variable. Those reporting higher levels of risk associated with family supports over the first and third year of release were also more likely to be re-arrested. The disintegration of a family dynamic could be a critical component when discussing successful rehabilitation and trust [38]. In the fifth year of followup, the ASI-6 continues to be an excellent predictor of re-arrest. This model, like the last two regression models, was found to be statistically significant (.001 with a confidence level of $95 \%$ with the $\mathrm{p}<.05$ being significantly different than zero) [40-41].The variance explained within this model was similar to the previous model predicting approximately $55.7 \%$ of re-arrest over a five year follow-up. This number is a conservative average of the Nagelkerke R Square at .639 and the Cox and Snell R Square at .474. The regression reported a Chi-square of 278.964 and a model -2 Log likelihood of 308.593. All three regression analyses had seven degrees of freedom. Therefore, even in its most conservative prediction model, not taking into account demographic data, its predictive power could be nearly $64 \%$ over a five-year period since an offender had taken their original ASI-6 intake. It could be argued that the ASI is a very good predictor of immediate (one 
year), short term (three year) and long term (five year) re-arrest [42-45].

Validating the Addiction Severity Index (ASI-6) on Offender Re-Arrest Similar to the logistic regression models on one- and three-year re-arrest, this study's findings suggest that the ASI6 can predict re-arrest at a greater strength over a longitudinal basis. Employment remains the most significant predictor of re-arrest over a five-year follow-up however, as the Beta values suggest, alcohol and drug abuse become a better predictor of long-term re-arrest than an offender's ASI-6 metrics of legal or psychological needs. As such, it appears that anecdotally speaking, many of the barriers that were once identified at initial intake for offenders have not been adequately dealt with and as a result, an offender's likelihood to desist from crime is decreasing. Therefore, it appears that if these needs and risks do not get the proper attention, intervention and/or treatment result in future re-arrest [46-52]. Therefore, allocating the appropriate resources based on the ASI- 6 domain metrics measuring composite high and severe risk scores were more valuable in assessing future re-arrest. The higher an offender scored on their composite seven domains, the more likely they will be re-arrested for a crime over one, threeand five-year intervals.

\section{Implications}

After being released from jail and/or prison, offenders were offered the opportunity to enroll in a federally funded (SAMHSA) Access to Recovery (ATR) alcohol and other drug abuse treatment program. Findings of the study could support that the ATR program was somewhat successful as their rates of re-arrest were lower than other national studies [29]. However, further investigation into intake information, using the Addiction Severity Index, version 6 (ASI-6) reveals that those who score highly on composite scores within each of the seven domains are also more likely to be re-arrested over one, three and/or five year periods upon release. Overall, the purpose of this study was the evaluation of the Addiction Severity Index (ASI version 6) in predicting the re-arrest of 434 offenders over one, three- and five-year intervals. Based on the findings of the logistic regression models, the ASI6 was able to predict anywhere from $43 \%, 58 \%$ and $56 \%$ of rearrest within first, third and fifth year of an offender's release from custody (respectfully) [53-59]. The predictive variance explained of this magnitude suggests that the use of the ASI-6 as a clinical tool is a very good predictor of both short term and long-term re-arrest. Also consider that the study's findings did not include additional demographic information (sex, age, race, ethnicity, marital status) as predictive variables. All of these variables we know are highly correlated or related to criminal reoffending [1,37-38]. This study removed those variables in an attempt to understand the true predictive power of the ASI- 6 . The ASI-6 which uses similar conceptualization and operationalization techniques as developed through the RNR approach by Andrews et al. $[13,14]$. Ensuring quality intake assessment is integral to attaining baseline data on offenders that could assist them in desisting from future criminal activity. While this study certainly has limitations including but not limited to a lack of random selection, a comparison group and interval level markers of the ASI-6, it highlights the need for statistics and analytics rather than practitioner discretion in decision making. Utilizing risk assessment within intake assessments has become a normative approach to doing community based corrections however, it often does not differentiate between the levels of severity of risks and needs each offender has. As practitioners and clinicians can attest, offenders often have many deficits and as a result, a strength based holistic approach to rehabilitation is what is offered to offenders. While taking a holistic approach to rehabilitation is wise, targeting risk and need and prioritizing those over others allows for practitioners to target areas of immediate concern [5461]. Using the ASI-6 to identify offenders who score high or severe on any one of the seven domains would go a long way in placing priority on at-risk factors such as employment, legal expectations for terms and conditions, psychological/ medical assistance as well as alcohol and other drug use. While this particular Access to Recovery (ATR) site indicates some preliminary success in curbing re-arrest (as compared to other national studies of State correctional studies), the data should offer modest hope of success when intake assessment is utilized to target an offender's risks and needs. While offenders were re-arrested at a lower rate than other national studies, there is also the limitation of a lack of random selection, comparison groups and interval based ASI6 measurements [62-67]. The unfortunate reality is that many programs are able to undertake rigorous experimental designs and/or analysis without substantial funding [68-73]. As such, while this study has its limitations, it provides a modest and conservative validation of the Addiction Severity Index, version 6 (ASI-6) as a logistical instrument that can be used to identify both success and failure.

Consider the previous analogy of a Major League Baseball hitter who has a lifetime .300 batting average. Do we consider them failures? We may often fail more than we succeed but using that same premise, should we accept offender failure without using potential analytics that are available? Major League Baseball took a long time to adjust to sabermetrics [3] from the longevity of using the discretion experienced scouts and executives [74-76]. No one can argue that baseball was transformed for the better Perhaps the correctional system will embrace the implementation of more metrics and risk assessment tools to find more success rather than failure. As viewed through the lense of the movie Moneyball [2], analytics will require institutional change. The rise of analytics may take time to be implemented, but once it has been, it will be a game changer [77]. 


\section{References}

1. Sherman L, Gottfredson D, MacKenzie D, Eck J, Reuter P, et al. (1997) Preventing crime: What works, what doesn't, what's promising. College Park: University of Maryland Press.

2. Miller, Bennett (2012) Moneyball. Sony Pictures Home Entertainment, Culver City, CA: California, United States.

3. Lewis, Michael (2003) Moneyball: The Art of Winning an Unfair Game. W.W. Norton, New York.

4. Saccoman, John (2009) Practicing Sabermetrics: Putting the Science of Baseball Statistics to Work. McFarland and Company, New York.

5. Mäkelä K (2004) Studies of the reliability and validity of the Addiction Severity Index. Addiction 99: 398-410.

6. Scheurich A, Müller M, Wetzel H, Anghelescu I, Klawe C, et al. (2000) Reliability and validity of the German version of the European Addiction Severity Index (EuropASI). Journal of Studies on Alcohol 61(6): 916-919.

7. Koeter M, Hartgers C (1997) Preliminary Procedure for the Computation of the Europasi Composite Scores. Amsterdam: The Amsterdam Institute for Addiction Research.

8. Kokkevi A, Hartgers C (1995) Europ ASI: European adaptation of a multidimensional assessment instrument for drug and alcoho dependence. European Addiction Research 1: 208-210.

9. Cacciola J, Alterman A, Rutherford M, McKay J, Mulvaney F (2001) The relationship of psychiatric co-morbidity to treatment outcomes in methadone-maintained patients. Drug and Alcohol Dependence 61(3): 271-280.

10. Cacciola J, Rutherford M, Alterman A, Snider E (1994) An examination of the diagnostic criteria for antisocial personality disorder in substance abusers. Journal of Nervous and Mental Disease 182(9): 517-523.

11. Lesieur Henry, Blume S (1991) Evaluation of patients treated for pathological gambling in a combined alcohol, substance abuse and pathological gambling treatment unit using the Addiction Severity Index. British Journal of Addiction 86(8): 1017-1028.

12. McLellan A, Kushner H, Metzger D, Peters R, Smith I, et al. (1992) The fifth edition of the Addiction Severity Index, Journal of Substance Abuse Treatment 9(3): 199-213.

13. Andrews Don, Bonta J (1990) Classification for Effective Rehabilitation: Rediscovering Psychology. Criminal Justice and Behavior 17(1): 19-52.

14. Andrews D, Zinger I, Hoge R, Bonta J, Gendreau P, et al. (1990) Does Correctional Treatment Work? A Clinically Relevant and Psychologically Informed Meta-analysis. Criminology 28(3): 369-404.

15. Bourgon Guy (2009) Translating "What Works" into Sustainable Everyday Practice: Program Design, Implementation and Evaluation. Ottawa, ON: Public Safety Canada.

16. Leonhard C, Mulvey K, Gastfriend D, Schwartz M, Wei H (2000) The addiction severity index: A field study of reliability and validity. Journal of Substance Abuse Treatment 18(2): 129-135.

17. Hendriks V, Kaplan C, Van Limbeek J, Geerlings P (1989) The Addiction Severity Index: reliability and validity in a Dutch addict population. Journal of Substance Abuse Treatment 6(2): 133-141.

18. Petersilia, Joan (2004) What Works in Prisoner Reentry? Reviewing and Questioning the Evidence. Federal Probation 68(2): 4-8.

19. Petersilia JS, Turner S (1990) Comparing intensive and regular supervision for high-risk probationers: Early results from an experiment in California. Crime and Delinquency 36(1): 87-111.
20. Glaze Lauren, Kaeble D (2014) Correctional Populations in the United States, 2013. Bureau of Justice Statistics (BJS), Washington, DC: US.

21. Sabol W, Minton T, Harrison P (2007) Prison and Jail Inmates at Midyear 2006. US Bureau of Justice Statistics. US Department of Justice, Washington DC, US.

22. Glaze Lauren, Herberman E (2013) Correctional Populations in the United States 2012. Bureau of Justice Statistics (BJS), Washington, DC: US.

23. Feeley MM, Simon J (1992) The New Penology: Notes on the Emerging Strategy for Corrections, Criminology 30(4): 449-474.

24. Hannah-Moffat K, Maurutto P, Turnbull S (2010) Negotiated Risk: Actuarial Assessment and Discretion in Probation. Canadian Journal of Law and Society 24(3): 391-409.

25. Rothstein Henry, Huber M, Gaskell G (2006) A Theory of risk colonization: The spiraling regulatory Logics of Societal and Institutional Risk. Economy and Society 35(1): 91-112.

26. Harris, Patricia (2006) What Community Supervision Officers Need to Know about Actuarial Risk Assessment and Clinical Judgment, Federal Probation 70.

27. Beck, Aaron, Harrison P (2001) Prisoners in 2000. US Department of Justice. Bureau of Justice Statistics, Washington DC, US.

28. Grissom, Grant, Bragg A (1991) Addiction Severity Index: Experience in the field. International Journal of the Addictions 26(1): 55-64.

29. DuRose, Matthew, Cooper A, Snyder H (2014) Special Report: Recidivism of Offenders Released in 30 States in 2005: Patterns from 2005 to 2010. Department of Justice, Bureau of Justice Statistics Washington DC, US.

30. Langan, Patrick, Levin D (2002) Recidivism of Prisoners Released in 1994. US Department of Justice. Washington, DC: Bureau of Justice Statistics, Washington, DC, US.

31. Taxman F, Cherkos R (1995) Intermediate sanctions: Dealing with technical violators. Corrections Today 57: 46-57

32. Petersilia, Joan (2000) When Prisoners Return to the Community Political, Economic and Social Consequences. Sentencing and Corrections Issues for the $21^{\text {st }}$ Century. National Institute of Justice Research in Brief, No. 9. US Department of Justice, Washington DC, US.

33. Substance Abuse \& Mental Health Services Administration (SAMHSA) (2006) Access to Recovery Programming.

34. Tonry, Michael, Wilson J (1990) Drugs and crime. Chicago: University of Chicago Press, United States.

35. Farabee D, Prendergast M, Anglin M (1998) The effectiveness of coerced treatment for Drug abusing offenders. Federal Probation 62: 3-10.

36. Gendreau Paul (1996) Offender Rehabilitation: What We Know and What Needs to Be Done. Criminal Justice and Behavior 23(1): 144-161.

37. Taxman F, Young D, Byrne J (2003) Offenders View of Reentry: Implications for Processes, Programs, and Services. National Institute of Justice, Washington DC, US.

38. Visher C, Kachnowski N, La Vigne N, Travis J (2004) Baltimore Prisoners Experiences Returning Home: The Urban Institute, Washington, DC, US.

39. Aos S, Miller M, Drake E (2006) Evidence Based Adult Corrections Programs: What Works and What Does Not. Olympia, WA: Washington State Institute for Public Policy.

40. Belenko Steven (2000) Diversion programs: Providing treatmentbased alternatives to incarceration for drug-involved criminal offenders. Connection 12: 1-8. 
41. Belenko, Steven, Peugh J (2005) Estimating drug treatment needs among state prison inmates. Drug and Alcohol Dependence 77(3) 269-281.

42. Belenko S, Foltz C, Lang M, Sung H (2004) The impact on recidivism of residential treatment for high-risk drug felons: A longitudinal analysis. Journal of Offender Rehabilitation 40: 105-132.

43. Bonczar, Thomas, Glaze L (1999) Probation and Parole in the United States, 1998. U.S. Department of Justice. Bureau of Justice Statistics, Washington, DC, US

44. Butler R, Budman S, Goldman R, Newman F, Beckley E, et al. (2001) Initial validation of a computer-administered addiction severity index: ASI-MV. Psychology of Addictive Behaviors 15(1): 4-12.

45. Center on Addiction and Substance Abuse (1998) Behind bars: Substance abuse and America's prison population. New York: Center on Addiction and Substance Abuse.

46. Clear T, Rose D, Ryder J (2001) Incarceration and the Community: The Problem of Removing and Returning Offenders. Crime and Delinquency 47(3): 335-351.

47. Corse SJ, Zanis D, Hirschinger N (1995) The use of the Addiction Severity Index with people with severe mental illness. Psychiatric Rehabilitation Journal 19(1): 9-18.

48. Cullen, Francis, Gendreau P (2000) Assessing Correctional Rehabilitation: Policy, Practice, and Prospects, in NIJ Criminal Justice 2000: Changes in Decision Making and Discretion in the Crimina Justice System. Department of Justice. National Institute of Justice, Washington, DC: US.

49. Goldstein Paul (1985) The drugs/violence nexus: A tripartite conceptual framework. Journal of Drug Issues 15(4): 493-506.

50. Hammett T, Roberts S, Kennedy S (2001) Health-Related Issues in Prisoner Reentry to the Community. Crime and Delinquency 47(3): 390-409.

51. Harrison Lana (2001) The Revolving Prison Door for Drug-Involved Offenders: Challenges and Opportunities. Crime and Delinquency 47(3): 462-485

52. Harrison, Paige Beck A (2004) Prisoners in 2003. US Department of Justice. Bureau of Justice Statistics, Washington DC, US

53. Harrison, Paige, Karberg J (2004) Prison and jail inmates at midyear 2003. US Department of Justice. Bureau of Justice Statistics, Washington, DC, US

54. Hughes T, Wilson D, Beck A (2001) Trends in State Parole, 1990-2000. US Department of Justice. Washington, DC: Bureau of Justice Statistics, Washington, DC, US

55. Inciardi J, Martin S, Butzin C (2004) Five-year outcomes of therapeutic community treatment of drug-involved offenders after release from prison. Crime and Delinquency 50(1): 88-107.

56. Knight K, Simpson D, Hiller M (2002) Screening and referral for substance-abuse treatment in the criminal justice system. In: Leukefeld CG, Tims F, Farabee D (Eds.), Treatment of drug offenders: Policies and issues. Springer, New York.

57. Langan P, Schmitt E, Durose M (2003) Recidivism of Sex Offenders Released from Prison in 1994. Bureau of Justice Statistics. Washington, D.C.: U.S. Department of Justice, Washington, DC: US.

58. Leshner AI (1998) Drug addiction research: Moving toward the 21st century. Drug and Alcohol Dependence 51(1-2): 5-7.
59. Lipton D, Pearson F, Wexler H (2000) Final report: National evaluation of the Residential Substance Abuse Treatment for state prisoners program from onset to midpoint. Washington, DC: National Institute of Justice.

60. Lynch, James, Sabol W (2001) Prisoner Reentry in Perspective. Crime Policy Report. Urban Institute Press, Washington, DC.

61. Martin S, Butzin C, Saum C, Inciardi J (1999) Three-year outcomes of therapeutic community treatment for drug involved offenders in Delaware: from prison to work release to aftercare. The Prison Journal 79(3): 294-320.

62. McLellan T, Caccoila J, Alterman A (2004) Commentaries on Mäkelä. Addiction 99: 411-413.

63. McLellan A, Woody G (1998) Evaluating the effectiveness of treating drug abusers effectively. Malden, MA: Blackwell

Publishers, New Jersey, United States.

64. McLellan A, Luborsky T, O’Brien C (1982) Is treatment for substance abuse effective? Journal of the American Medical Association. 247(10): 1423-1428.

65. Mumola, Christopher (1999) Substance Abuse and Treatment, State and Federal Prisoners, 1997. US Department of Justice. Bureau of Justice Statistics, Washington DC, US

66. Mumola, Christopher (2000) Incarcerated parents and their children U.S. Department of Justice. Bureau of Justice Statistics, Washington DC, US.

67. Nurco DN (1998) A long term program of research on drug use and crime. Substance Use and Misuse 33(9): 1817-1838.

68. Pearson F, Lipton D (1999) A meta-analytic review of the effectiveness of corrections based treatments for drug abuse. The Prison Journal 79(4): 384-410.

69. PEW Charitable Trusts (2008) One in 100: America Behind Bars 2008.

70. Rosen C, Henson B, Finney J, Moos R (2000) Consistency of selfadministered and interview-based Addiction Severity Index composite scores. Addiction 95(3): 419-425.

71. Seredycz Michael (2010) Offender Drug Abuse and Recidivism: An Access to Recovery Program. El Paso, TX: LFB Scholarly Publishing LLC.

72. Tonry, Michael, Petersilia J (1999) Prison Research at the Beginning of the $21^{\text {st }}$ Century. National Institute of Justice Lectures on Criminal Justice.

73. Tonry, Michael (1998) The Handbook of Crime and Punishment. Oxford University Press, New York

74. Travis, Jeremy (2000) But they all come back: Rethinking prisoner reentry. National Institute of Justice, Washington D.C, US.

75. Travis J, Cincotta E, Solomon A (2003) Families Left Behind: The Hidden Costs of Incarceration and Reentry. The Urban Institute, Washington, D.C, US.

76. Walmsley, Roy (2013) World Prison Population List. (10 $10^{\text {th }}$ edn), London UK: King's College: International Center for Prison Studies.

77. Wilson James (2000) Crime: Public Policies for Crime Control. $2^{\text {nd }}$ edn), ICS Press Oakland, CA: California. 
This work is licensed under Creative Commons Attribution 4.0 License

DOI: 10.19080/ASM.2020.05.555655
Your next submission with Juniper Publishers will reach you the below assets

- Quality Editorial service

- Swift Peer Review

- Reprints availability

- E-prints Service

- Manuscript Podcast for convenient understanding

- Global attainment for your research

- Manuscript accessibility in different formats

( Pdf, E-pub, Full Text, Audio)

- Unceasing customer service

Track the below URL for one-step submission https://juniperpublishers.com/online-submission.php 